\title{
FDA Stability Data Standards Terminology
}

National Cancer Institute

\section{Source}

National Cancer Institute. FDA Stability Data Standards Terminology. NCI Thesaurus.

Code C96069.

Terminology developed to support the Stability Data Standards, a cooperative effort between the Food \& Drug Administration (FDA) and Health Level Seven (HL7). 